\title{
Variation of Lichen Diversity along an Elevation Gradient in the Hantana Mountain Range in Sri Lanka
}

\author{
Weerathunga W.A.M.T.*, Athappaththu A.M.G.K. \\ Department of Zoology and Environmental Management, University of Kelaniya, Sri Lanka \\ *manaseew@yahoo.com
}

Lichens are composite organisms formed by symbiotic relationships between algae or cyanobacteria and fungi. Apart from their morphological diversity, lichens hold a major significance in ecology because of their role as biological indicators. Lichens are highly sensitive to environmental stresses, such as air pollution and climate change. Accordingly, the objective of this study was to determine the variation of lichen diversity in the Hantana mountain range along an elevation gradient. Five elevations ranging from 512 to $773 \mathrm{~m}$ above mean sea level (amsl) were selected in the Hantana mountain range, Peradeniya. The tree species selected for surveying lichens was Alstonia macrophylla because of its availability at all elevations. Two trees were selected randomly from each elevation. In each tree, a monitoring quadrate containing five independent $5 \times 5 \mathrm{~cm}$ quadrate segments was hung at $1 \mathrm{~m}$ from ground level. Lichens in quadrate segments were surveyed using a hand lens, and taxonomically identified using standard pictorial keys. The area of each lichen was measured using ImageJ software (Version 1:51k). In each tree trunk, four sides facing the four directions (North, East, West, and South) were surveyed independently. The Lichen Diversity Values (LDV) and the Indices of Atmospheric Purity (IAP) were calculated for each elevation. With the exception of one site at 583m amsl, the LDV showed a positive exponential relationship $\left(\mathrm{LDV}=25.161 * \mathrm{e}^{0.0024 * \mathrm{E}}, \mathrm{R}^{2}=0.76\right)$ with increasing elevation $(\mathrm{E})$. Reduction of air temperature and partial pressure of $\mathrm{CO}_{2}\left(\mathrm{pCO}_{2}\right)$ with increasing altitude could have contributed to the increasing lichen diversity. The lowermost site (L1) at $512 \mathrm{~m}$ showed the lowest LDV (95) while the uppermost site (L5) at $773 \mathrm{~m}$ showed the highest LDV (191). In addition to the natural variation of $\mathrm{pCO}_{2}$, proximity to roads with frequent vehicular traffic could have influenced the observed variation of LDV with elevation. The site at $583 \mathrm{~m}$, which did not fit in to the positive exponential relationship, had a higher LDV value (187) than that predicted from the relationship (102) probably because it was the least exposed to vehicular traffic. At all elevations, IAP values were greater than 50, which indicated that they have very low air pollution, indicating the importance of conservation programs. However, the presence of highly sensitive lichen genera such as Physica and Leptotrema being limited only to sites at upper elevations indicate that those sites are less polluted. On the other hand, lichen genera Megalospora, Graphis and Wirthiotrema were observed at all elevations.

Keywords: Lichen diversity, Elevation gradient, Hantana range, Air pollution, $\mathrm{pCO}_{2}$ 